\title{
Superhydrophilic Smart Coating for Self-Cleaning Application on Glass Substrate
}

\author{
A. Syafiq, ${ }^{1}$ B. Vengadaesvaran $\left(\mathbb{D},{ }^{1}\right.$ A. K. Pandey, ${ }^{2}$ and Nasrudin Abd. Rahim $\mathbb{D}^{1,3}$ \\ ${ }^{1}$ UM Power Energy Dedicated Advanced Centre (UMPEDAC), University of Malaya, Level 4, JalanPantai Baharu, \\ 59990 Kuala Lumpur, Malaysia \\ ${ }^{2}$ Research Centre for Nano-Materials and Energy Technology (RCNMET), School of Science and Technology, Sunway University, \\ No. 5, Jalan Universiti, Bandar Sunway, Petaling Jaya, 47500 Selangor Darul Ehsan, Malaysia \\ ${ }^{3}$ Renewable Energy Research Group, King Abdulaziz University, Jeddah 21589, Saudi Arabia
}

Correspondence should be addressed to B. Vengadaesvaran; venga@um.edu.my and Nasrudin Abd. Rahim; nasrudin@um.edu.my

Received 4 June 2018; Revised 24 August 2018; Accepted 27 September 2018; Published 3 December 2018

Academic Editor: Ping Xiao

Copyright @ 2018 A. Syafiq et al. This is an open access article distributed under the Creative Commons Attribution License, which permits unrestricted use, distribution, and reproduction in any medium, provided the original work is properly cited.

\begin{abstract}
In general, superhydrophilic coating on glass substrate possesses water contact angle (WCA) below $10^{\circ}$ and contains high self-cleaning properties in outdoor environment as compared to noncoated glass substrate panels. In this study, the superhydrophilic coating behavior on glass substrate has been developed. The micro- and nanosized titanium dioxide $\left(\mathrm{TiO}_{2}\right)$ particles have been utilized to improve the surface roughness, and the polypropylene glycol (PPG) has been utilized to increase the surface energy of glass substrates. The wettability of coating surface shows the coating possess water contact angle (WCA) as low as $5^{\circ}$ and suddenly reduce to $0^{\circ}$ after $10 \mathrm{~s}$. Superhydrophilic coated glass clearly shows excellent dirt repellent against dilute ketchup solution due to the absence of dirt streak on the glass surface. Meanwhile, the dirt streak is present on the bare glass surface indicating its weak self-cleaning property. The developed superhydrophilic coating on glass substrate was also found to have great antifog property compared to the bare glass substrate. Superhydrophilic surfaces have showed free tiny droplet even at $130^{\circ} \mathrm{C}$ of hot boiling bath for $10 \mathrm{~min}$ and completely dry after $1 \mathrm{~min}$. The superhydrophilic coating surfaces have demonstrated free water streak after impacting with harsh water spraying for $5 \mathrm{~min}$ confirming that the superhydrophilic coating on glass substrate is antiwater streak.
\end{abstract}

\section{Introduction}

Metal oxides in surface coatings are widely applied in antireflection, self-cleaning [1-3], and antifogging [4-7] of superhydrophilic glass. Numerous research works are attempted to develop highly efficient self-cleaning glass surfaces with advanced optical qualities for solar panel applications. For example, TitanProtect ${ }^{\circledR}$ [8] has developed an excellent selfcleaning-coated solar panel where the coated panels have presented a clear reduction in reflection by $65 \%$ relative to the uncoated panel. This is because the dust and dirt on the coated panel were rinsed off during rainfalls. Self-cleaning superhydrophilic glass coating also has been developed by TitanShield solar coat [8] through the photocatalyst reaction and nanotechnology fabrication. Superhydrophilic coating can be achieved by UV irradiation. Adachi et al. [9] have reported that their superhydrophilic $\mathrm{TiO}_{2} / \mathrm{SiO}_{2} \quad\left(\mathrm{TiO}_{2}\right.$ : $\mathrm{SiO}_{2}=8: 2$ ) coating could achieve superhydrophilic property after UV irradiation for $300 \mathrm{~min}$. The WCA changes from $48^{\circ}$ to $10^{\circ}$ after UV irradiation for $60 \mathrm{~min}$, and the WCA further reduced to $5^{\circ}$ after UV irradiation for $120 \mathrm{~min}$. Instead of light radiation, the superhydrophilicity can be achieved by process condition such as concentration and $\mathrm{pH}$ or the proper nanoparticle size. Cebeci et al. [10] have prepared the superhydrophilic nanoporous thin film by layer-bylayer assembled silica nanoparticles and a polycation where the superhydrophilicity of coating has been controlled by different concentrations of nanoparticles and $\mathrm{pH}$ of $\mathrm{HCl}$ or $\mathrm{NaOH}$. The result showed that the coating could achieve below $2^{\circ}$ and can retain the superhydrophilicity for at least $168 \mathrm{~h}$ at $50^{\circ} \mathrm{C}$ when the concentration of nanoparticles is at $0.03 \mathrm{wt} \%$ of silica nanoparticles. Du et al. [11] have 
prepared the superhydrophilic dendrimer-like mesoporous silica nanoparticle (DMSN) coating by increasing the roughness of coating. The particle size and pore size of DMSNs slightly decrease when subjected to calcination at $550^{\circ} \mathrm{C}$, as a result of the WCA of originated DMSNs from $24^{\circ}$ to $2.2^{\circ}$ after $0.5 \mathrm{~s}$ of spreading on the surface of glass slides. It was concluded that the appropriate particles and pore size have constructed a transparent DMSN superhydrophilic and antifogging coating.

The photocatalysis and photoinduced hydrophilicity have stimulated the photocatalyst to distinguish the contaminants; however, the ultraviolet rays (UV) from sunlight are insufficient for photocatalysis reaction [12]. The $\mathrm{TiO}_{2}$ superhydrophilic thin films are commonly employed for photocatalysis reaction, but its energy band $\left(E_{\mathrm{g}} \approx 3.2 \mathrm{eV}\right)$ is limited to shorter UV radiation with wavelength lower than $387.5 \mathrm{~nm}$ [13]. Besides, UV light is a small part of solar light radiation (about 5\%) [14]. Several research studies suggested the doping of the titanium dioxide with metal and nonmetal elements which extended the photoresponse of $\mathrm{TiO}_{2}$ to the visible light range and enhanced the degradation rate of contaminants [15-21]. However, it is hard to maintain photocatalysis reaction of film for self-cleaning purposes especially at low solar light radiation, as a result the photoactive coating is being deactivated [22]. Because of this limitation of photocatalysis reaction, the development of hierarchical surface textures is highly recommended for superhydrophilic coating $[10,23-25]$. In contrast to photocatalysis reaction, a multilayer of hierarchical nanostructures self-cleans the surface through liquid spreading action mechanism. Chen et al. [26] have reported that the strong hydrogen bond between the silica nanoparticle thin coating (SNT) film surface and water molecule caused the water to spread uniformly on surface. Hence, the water can remove peanut oil from the surface. But the mechanical strength of the superhydrophilic coating without the strong adhesion between the coating and substrate is still doubtful; hence, it is useful to use the suitable binder to achieve strong adhesion coating.

Polydimethylsiloxane (PDMS) is well known for its hydrophobicity due to its low surface tension and has been employed to develop hydrophobic and superhydrophobic coatings as reported by most research studies. PDMS is commonly used for surface binder, and its low cost compared to other binders and hydrophilic polymers has attracted the researchers to develop the hydrophilic or superhydrophilic coating by using or modifying the PDMS. Currently, various methods have been employed to enhance the surface hydrophilicity of PDMS including plasma treatment, ultraviolet irradiation, corona discharge, and coating or grafting hydrophilic polymers onto PDMS surface [27]. Zhang et al. [27] have reversed the hydrophobic PDMS to hydrophilic by 1-step hydrolysis reaction of Si-O bond to generate a hydrophilic hydroxyl group. 2-(Trimethylsiloxy)ethyl methacrylate (TMSEMA) is used as their hydrophilizing reagent. The result showed that the WCA of pristine PDMS dropped from $94^{\circ}$ to $15^{\circ}$ after incorporating with $15 \mathrm{wt} \%$ of TMSEMA and the coating is not considered as superhydrophilic property. Rahimi et al. [28] have developed hydrophobic/hydrophilic Janus paper which is irreversibly bonded to PDMS substrate via corona discharge surface treatment. The WCA of the corona-treated polymer is reduced from $98^{\circ}$ to $22^{\circ}$ when the discharge duration is increased. However, this study cannot assure the durability of their surface hydrophilicity due to the surface enrichment of the siloxane. The proposed method by grafting the hydrophilic polymers on PDMS $[29,30]$ is too complicated and requires multiple steps of fabrication on the PDMS. Unlike the previous studies, our PDMS coating achieved superhydrophilic property with easy fabrication on large-scale glass substrate and simple processing without heat treatment or calcination process and can be cured at room temperature. Polypropylene glycol is employed as a hydrophilizing agent, and $\mathrm{TiO}_{2}$ particles have been used as inorganic particles. From the previous superhydrophilic studies, $\mathrm{TiO}_{2}$ particles is well known for its hydrophilicity [31-33]. The incorporation of $\mathrm{TiO}_{2}$ also can degrade the WCA of PDMS as reported by Cui et al. [34]. It was reported that the hydrophilic $\mathrm{TiO}_{2}$ coating reduces the CA of PDMS coating from $102^{\circ}$ to $98^{\circ}$ when the content of $\mathrm{TiO}_{2}$ was low at 4 and $6 \mathrm{wt} \%$. Our superhydrophilic coating exhibit an excellent self-cleaning property without the UV assistance, and the coating also showed great antifog as well. The coating can retain its superhydrophilicity after 6 days indicating good surface durability.

\section{Experimental Methods and Materials}

2.1. Materials. All chemicals in this study were used without any further purification. Titanium dioxide $\left(\mathrm{TiO}_{2}\right.$, Degussa P25) powder with sizes of $100 \mathrm{~nm}$ and purity at $99.99 \%$ and micropowder of $\mathrm{TiO}_{2}$ with sizes of $40 \mu \mathrm{m}$ at purity of $99 \%$ were used as inorganic nanoparticles and were obtained from Sigma-Aldrich, Malaysia. Polydimethylsiloxane (PDMS) with density of $5 \mathrm{~g} / \mathrm{ml}$ and viscosity of $100 \mathrm{mPa}$ at $25^{\circ} \mathrm{C}$ is employed as a surface modifier and is purchased from Acros Organics, Malaysia. Polypropylene glycol (PPG) with viscosity of $100 \mathrm{mPa} \cdot \mathrm{s}$ at $20^{\circ} \mathrm{C}$ and density of $1.01 \mathrm{~g} / \mathrm{ml}$ at $20^{\circ} \mathrm{C}$ is employed as a hydrophilic agent which has been employed from Sigma-Aldrich, Malaysia. Ethanol with purity of $99.8 \%$ and molecular weight of 46.07 is used as base solution and a cleaning agent for glass. Isopropyl alcohol (2-propanol) with molarity of $60.10 \mathrm{~g} / \mathrm{mol}$ is used as a curing agent for organic solution. Both ethanol and isopropyl alcohol were purchased from Sigma-Aldrich, Malaysia.

2.2. Substrate Preparation. In this study, the glass slide with dimension size of $20 \mathrm{~mm} \times 20 \mathrm{~mm}$ and glass plates $(100 \mathrm{~mm} \times 200 \mathrm{~mm})$ were used as substrate. The substrates were cleaned by using ethanol in order to remove the contaminants on the glass surface. Then, the glass slides were rinsed with distilled water to remove the hydroxyl contaminants, and these glasses were then dried under room temperature at $25^{\circ} \mathrm{C}$ for a period of $1 \mathrm{~h}-2 \mathrm{~h}$.

2.3. Thin Film Deposition. Firstly, $\mathrm{TiO}_{2}$ nanopowders and micropowders were dissolved in ethanol with weight ratio of $1: 2: 10$ and were stirred vigorously using a magnetic stirrer inside the $2 \mathrm{wt} \%$ hydrophilic agent PPG for $30 \mathrm{~min}$. The dissolved powder then was subjected to sonication in 
ultrasonic bath at $50^{\circ} \mathrm{C}$ for another $30 \mathrm{~min}$ in order to disperse the nanoparticles well in the ethanol solution. Secondly, PDMS resin was dissolved in isopropyl alcohol at weight ratio of $3: 10$ and stirred using magnetic stirrer for $15 \mathrm{~min}$ to dilute the resin. Thirdly, the $10 \mathrm{wt} \%$ of prepared nanoparticles and microparticles was blended together with $50 \mathrm{wt} \%$ of diluted PDMS resin and $20 \mathrm{wt} \%$ of a hydrophilic agent PPG vigorously for $30 \mathrm{~min}$ before subjecting to sonication at $30^{\circ} \mathrm{C}$ for $15 \mathrm{~min}$. The prepared solution coating system was applied on the glass slides using dip-coating technique. Meanwhile, the above-developed solution was applied on the glass plates using brushing technique. Both glass samples were then left to dry for 1 day before they are employed to perform all tests.

\subsection{Characterizations and Testings}

2.4.1. Water Contact Angle (CA) Analysis. The hydrophilicity of $\mathrm{TiO}_{2} / \mathrm{PDMS}$ coating was analyzed using water contact angle measurement. The contact angles of the droplets of distilled water were measured using the optical contact angle $15 \mathrm{EC}$ instrument where $5 \mu \mathrm{l}$ water droplet was dispensed at $2 \mu \mathrm{l} / \mathrm{s}$ by using the automated dispensing system on the coated glass and bare glass surface. The images of dispensed water droplets were recorded in order to measure the static contact angle.

2.4.2. Coating Surface Morphology. The surface topographical of the $\mathrm{TiO}_{2} /$ PDMS coating and bare glass were investigated using field emission scanning electron microscope (FESEM) Hitachi model of SU8220 (Hitachi, Japan). Secondary electron detector (SED) is objected to scan the microand nanograph images of surface roughness of coating and nanoparticle distribution under magnification of $5 \mu \mathrm{m}$ and $500 \mathrm{~nm}$ by using $1 \mathrm{kV}$ low accelerating voltage.

2.4.3. Antifog Analysis. The antifog analysis has been performed as follows. The bare glass and the coated glass substrate were kept above boiling water bath at $130^{\circ} \mathrm{C}$ for $10 \mathrm{~min}$. Both glasses were placed onto a white A4 paper to investigate the formation of haze and tiny water droplets after harsh fogging. The optical comparison results were recorded using mobile lens camera and analyzed further.

2.4.4. Self-Cleaning Test. The self-cleaning performance of the highly transparent superhydrophilic surface was demonstrated with diluent-ketchup solution as a model for dirt contaminant. The diluent-ketchup sauce solution was prepared inside $150 \mathrm{ml}$ beaker. The ratio of diluent-ketchup solution to water is at $2: 5$. The dirt solution poured onto the glass surfaces. Then, the behavior of liquid dirt onto bare glass and $\mathrm{TiO}_{2} /$ PDMS-coated glass substrates was captured using mobile lens camera and analyzed.

2.4.5. Rainfall Spraying Test. Rainfall spraying test has been conducted using an autosprayer onto the coated glass and bare glass substrates. Both glasses were placed against the autosprayer with horizontal distance between spray and the glass is at $10 \mathrm{~cm}$. The setup was illustrated in Figure 1. Water was sprayed continuously on both glass surfaces for $5 \mathrm{~min}$.

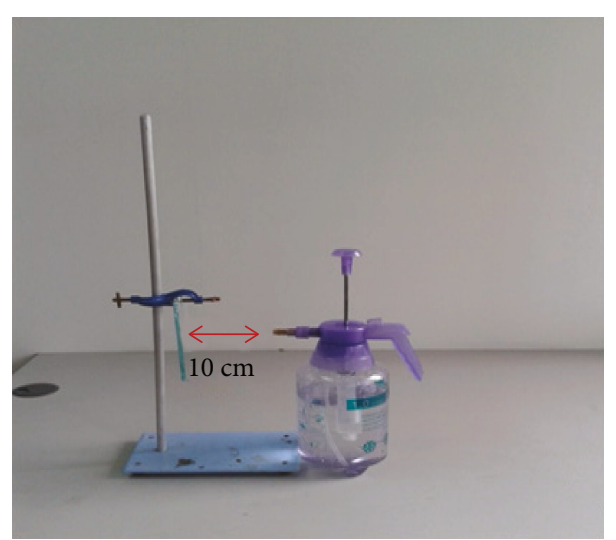

FIgURE 1: The experiment setup for rainfall spraying.

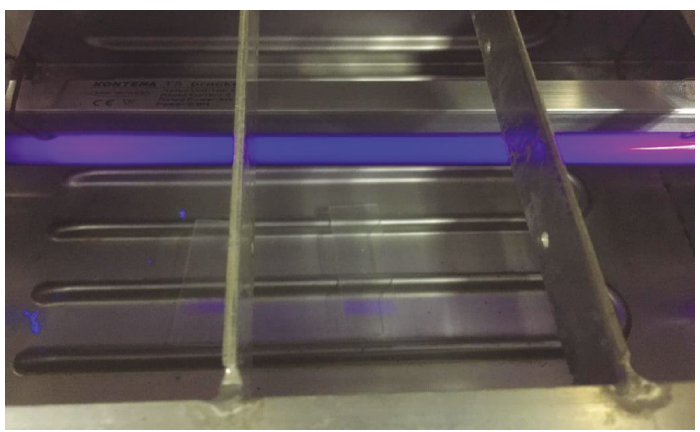

FIgURE 2: The setup of UV light illumination test.

The water streaks on both glass substrates have been captured using mobile lens camera after harsh water spraying and were analyzed.

2.4.6. Thickness of Coating. The thickness of the applied coatings on the glass substrate has been determined by an ellipsometer. The data were acquired and analyzed by using the WVASE32 (ex situ) and CompleteEASE (in situ/ex situ) software. The spectrum was recorded in the NIR region by M-2000 in the range of $193 \mathrm{~nm}$ to $1690 \mathrm{~nm}$. The thickness of coating on the glass slide has been recorded at $526.2 \pm 0.6 \mathrm{~nm}$.

2.4.7. UV Light Illumination Test. The WCA of modified $\mathrm{PDMS} / \mathrm{TiO}_{2}$ coating has been measured by using the optical contact angle 15EC instrument before UV light illumination. Next, the coated glass was placed in an incubator at $25^{\circ} \mathrm{C}$ and irradiated with UV-A light $(400 \mathrm{~nm}-320 \mathrm{~nm}, 300 \mathrm{~W})$ for 6 days as presented in Figure 2. The condition of the incubator and UV-A light has been monitored to avoid any problems during testing. After the 6th day of illumination, the coated glasses were placed outside and the WCA of coating was measured again. Any changes in contact angle of prepared coating have been recorded and analyzed.

2.4.8. Mechanical Properties of Coating. The microhardness and microscratch testing of coating are performed by using a MicroTest system (Micro Materials Ltd., Wrexham, UK). A pyramidal probe was pressed across the surface of the 


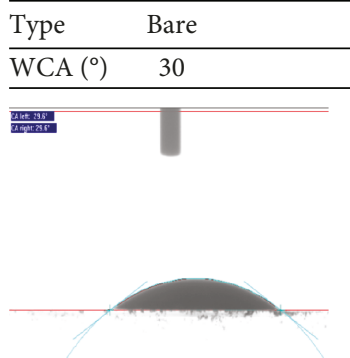

(a)

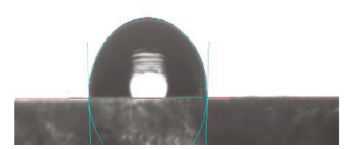

(b)

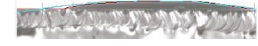

(c)

FIgURE 3: (a) The water CA of bare glass, (b) water CA of superhydrophilic coating, and (c) the water droplet spreading as thin film layer.

coating at pressing forces of $1.916 \mathrm{~N}(0.2 \mathrm{~kg})$ to investigate the hardness of coating. The microscratch test was applied on the coating by using a single-pass wear test mode in the instrument's software. The load was applied at $2100 \mathrm{mN}$, and the abrupt changes along the scratch tracks were observed over the scratch distance of $800 \mu \mathrm{m}$.

\section{Results and Discussions}

3.1. Water Contact Angle Analysis. The wettability of modified PDMS/ $\mathrm{TiO}_{2}$-coated glass substrate compared with bare glass substrate was measured using static water contact angle (WCA) measurements. The result of bare glass substrate showed WCA of $30^{\circ}$ indicating that the surface is in hydrophilic nature as shown in Figure 3. The WCA of the bare glass increases from $30^{\circ}$ to $92.6^{\circ}$ after modified with PDMS. The PDMS coating irreversibly changed from hydrophobic to superhydrophilic surface after surface modification and incorporating with solid nanoparticles. Firstly, the chemical composition of polymer-based glycol such as polypropylene glycol or polyethylene glycol plays a significant role in enhancing the hydrophilicity of the PDMS surface $[30,35]$. Secondly, the WCA of PDMS surface is further reduced by incorporating with hydrophilic micro- and nano- $\mathrm{TiO}_{2}$ particles [34]. The modified $\mathrm{PDMS} / \mathrm{TiO}_{2}$ glass substrate shows an excellent hydrophilicity with WCA $4.2^{\circ}$ and spreads the water like a thin film layer.

The WCA of modified PDMS/TiO 2 based coating shows an increase with time after placing the coated glass substrate in the dark environment for 2 days, 4 days, and 6 days as shown in Figure 4 . The result shows the static WCA of coating increases to $6.3^{\circ}$ after 2 days, further increases to $8.6^{\circ}$ after 4 days, and increases to $10.4^{\circ}$ after 6 days. The increase in WCA is directly inferred to the tendency of $\mathrm{TiO}_{2}$ to turn into hydrophobic behavior since $\mathrm{TiO}_{2}$ films have a rapid reestablishment of hydrophobicity in the dark environment. Several reports have proposed the doping of silicon dioxide $\left(\mathrm{SiO}_{2}\right)$ into $\mathrm{TiO}_{2}$ films to slow down the increases of WCA in dark environments [36-38]. However, doping with inorganic nanoparticles will cause high concentration of solid nanoparticles resulting in transparency degradation of coated glass substrate. In this study, we have blended the organic PDMS and PPG with $\mathrm{TiO}_{2}$ nanoparticles to provide high transparency on glass substrate and retain high hydrophilicity of $\mathrm{TiO}_{2}$ in dark environments. It can be observed that the

\begin{tabular}{|c|c|c|}
\hline Days & 4 & 6 \\
\hline WCA $\left(^{\circ}\right) 6.3$ & 8.6 & 10.4 \\
\hline 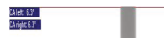 & & \\
\hline
\end{tabular}

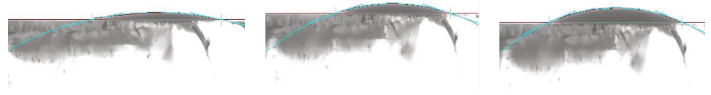

(a)

(b)

(c)

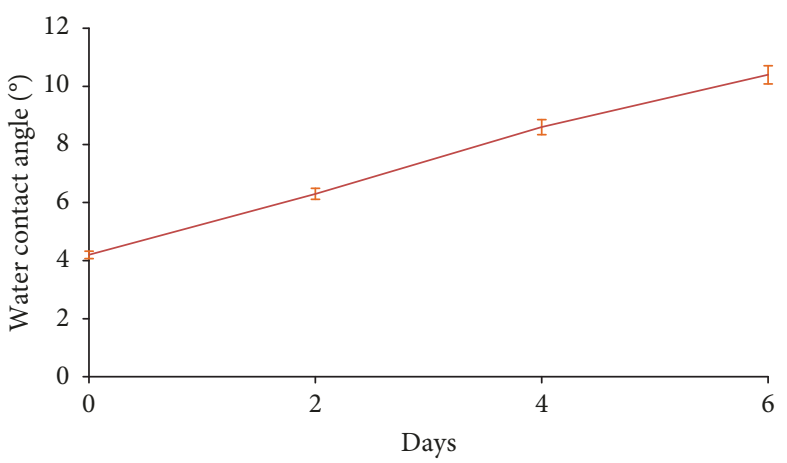

(d)

Figure 4: The water CA on superhydrophilic surface after (a) 2 days, (b) 4 days, and (c) 6 days. (d) The relationship between water CA and time of exposure is plotted in the graph.

WCA was maintained as low as $10.4^{\circ}$ after 6 days indicating that the coating has an excellent surface durability in the dark environment.

3.2. UV Light Illumination Analysis. Figure 5 compares the WCA of bare glass and modified $\mathrm{PDMS} / \mathrm{TiO}_{2}$ coating before and after UV light illumination. From the figure, it can be observed that the WCA of bare glass substrate reduces to a smaller value after incorporating with modified PDMS/ $\mathrm{TiO}_{2}$ coating. The WCA of treated substrate shifted from $31.7^{\circ}$ to $4.4^{\circ}$ indicating an excellent superhydrophilicity of coating. According to the Figure 5(c), the WCA of coating showed no significant changes where the WCA of coating slightly increases to $5.1^{\circ}$ after illuminated with UV light for 


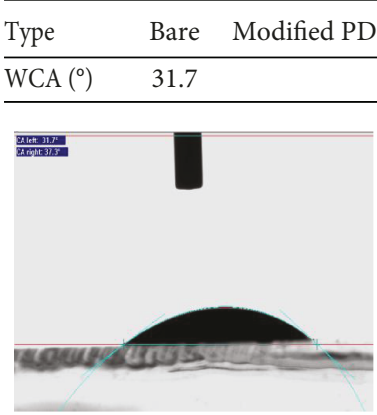

(a)

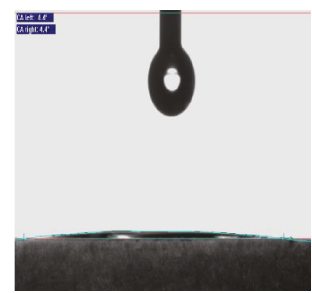

(b)

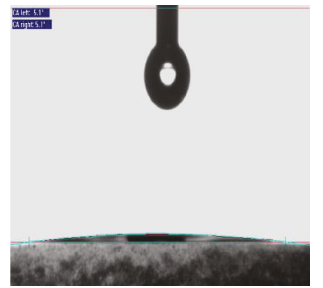

(c)

FIGURE 5: (a) The water CA of bare glass, (b) water CA of superhydrophilic coating, and (c) the water after illuminated with UV light for 6 days.

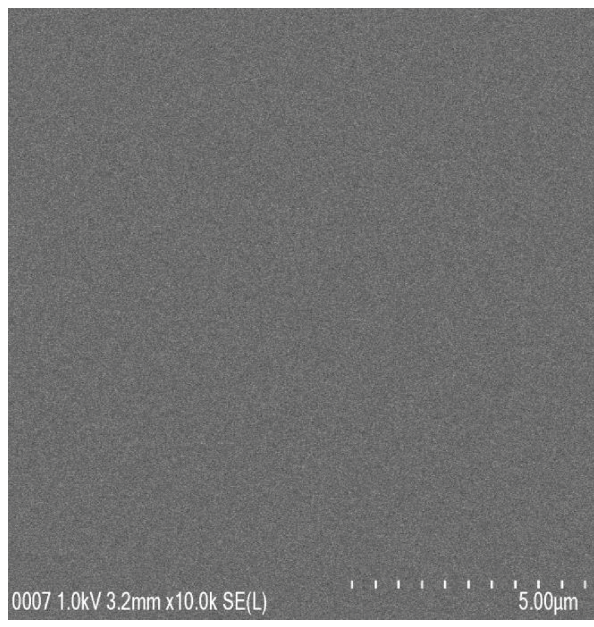

(a)

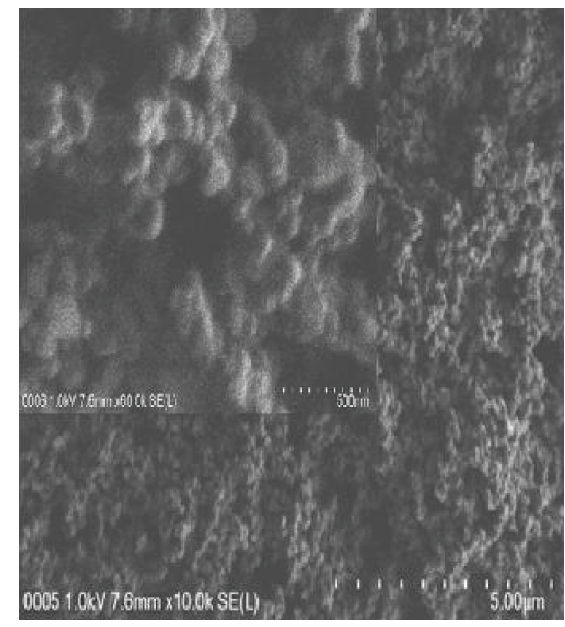

(b)

FIgURE 6: (a) The surface morphology of bare glass surface and (b) the surface morphology of $\mathrm{TiO}_{2} / \mathrm{PDMS}$ coating under magnification of $5 \mu \mathrm{m}$ and $500 \mathrm{~nm}$.

6 days. It is worth mentioning that the superhydrophilic property of coating was still maintained under prolonged UV light exposure. A slight deviation from the original value is due to absorptive pollutants, vapor of the liquid, and gas molecules on the coating's surface. These influences obstruct the contact angle of coating by introducing the molecular effects such as respective polarization of molecules or ions near the contact line [39].

3.3. Surface Morphological Analysis. Wettability of surface coating is strongly dependable on surface nanostructures and roughness. High hydrophilicity and hydrophobicity coatings commonly contain numerous amounts of nanostructures and high surface roughness. Figure 6 shows the FESEM micrograph of modified $\mathrm{PDMS} / \mathrm{TiO}_{2}$ coating. FESEM image revealed that the bare glass appears smooth with free of solid structures on the surface. Most of the literatures have suggested that the nanostructured surfaces improve the hydrophobicity of the surface $[12-14,16,17]$; however, there are some other nanostructured materials which transform the surface become more hydrophilic and superhydrophilic as shown in Figure 6. This decrement of WCA can be explained through the established Wenzel model. The basic assumption in Wenzel's theory is a linear relationship between apparent contact angle of the surface and the roughness factor of given surface:

$$
\cos \theta_{\mathrm{w}}=r \cos \theta
$$

where the roughness factor is the ratio of actual surface area to the apparent surface area. The rough surface presents the roughness factor, $r>1$, tuning the apparent contact angle to $\Theta_{w}>\theta>90^{\circ}$ for hydrophobic surface and $\Theta_{w}<\theta<90^{\circ}$ for hydrophilic surface. The surface roughness increases the hydrophobicity or hydrophilicity of coating which is strongly dependent on the surface nature. The heterogeneous morphology of modified $\mathrm{PDMS} / \mathrm{TiO}_{2}$ coating with increasing in surface roughness was observed in the obtained micrograph. From the obtained nanograph, the $\mathrm{TiO}_{2}$ micro- and nanoparticles are well dispersed within the polymeric glycol matrix without any cracks and phase dispersion. In general, the PPG can induce the water permeability and improve hydrophilicity on the target surface $[39,40]$. The microporous and nanopillars of $\mathrm{TiO}_{2}$ increase the surface roughness on hydrophilic PPG which later reduced the WCA of PDMS. As a result, the modified $\mathrm{PDMS} / \mathrm{TiO}_{2}$ coating performed an 

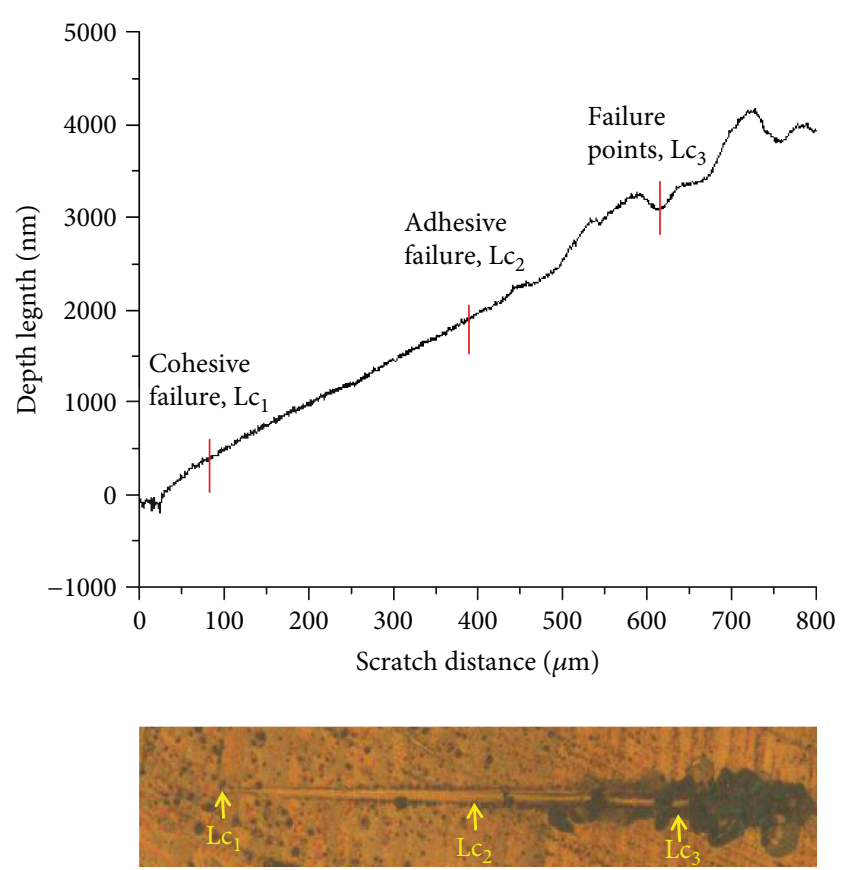

FIgURE 7: The abrupt changes in the residual scratch tracks after impact with $2100 \mathrm{mN}$ of the probe indenter.

excellent superhydrophilicity as mentioned in WCA measurement. Jimmy et al. [41] reported that the WCA of freshly prepared porous $\mathrm{TiO}_{2}$ thin film is at $15^{\circ}$ and the addition of polyethylene glycol (PEG) has reduced the WCA of porous $\mathrm{TiO}_{2}$ thin film to $<3^{\circ}$. At the same time, the roughness of porous $\mathrm{TiO}_{2}$ thin film is the indicator for the development of their superhydrophilic coating. The porous $\mathrm{TiO}_{2}$ thin film with rms of $1.18 \mathrm{~nm}$ showed the WCA at $15^{\circ}$ while the porous $\mathrm{TiO}_{2}$ thin film with rms of $41.96 \mathrm{~nm}$ showed the WCA below than $3^{\circ}$.

3.4. Mechanical Properties' Evaluation. The mechanical properties, in particular the adhesion of coating, are influenced by the intrinsic testing conditions and extrinsic film-substrate system. Intrinsic testing conditions include scratching speed, loading rate, and indenter shape while the extrinsic film-substrate system includes friction coefficient, surface condition, testing environment, and substrate and coating properties [42]. High stresses are required to break the bonding between the substrate and the coating; therefore, the indentation is the only testing method which can sufficiently generate high stresses. The scratch test is one of the developments from the indentation test [43]. The chronologies of the abrupt changes are defined as (a) Le-p: elasticto-plastic transition, (b) Lc1: cohesive failure due to chipping of the film, (c) Lc2: adhesive failure due to the delamination of film from its substrate, and (d) Lc3: total coating failure due to total exposure of the substrate surface $[44,45]$. Figure 7 shows graph of depth versus scratch distance of the coating during the scratch experiments. The abrupt changes along the scratch tracks have been presented by optical micrographs. Initially, the coating was in the elasticto-plastic transition mode [46].

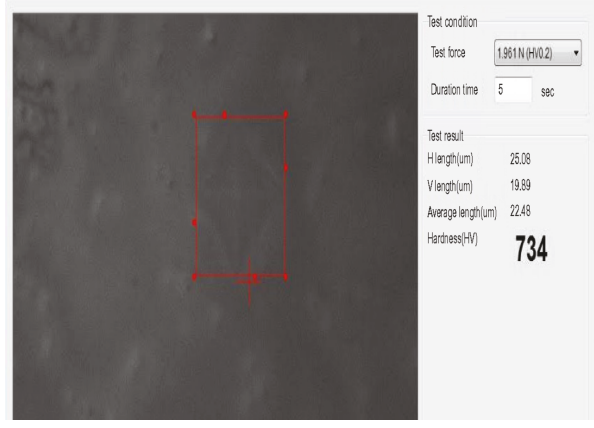

FIgURE 8: The microhardness on the prepared coatings.

From the figure, the prepared coating experienced a cohesive failure, Lc1 at scratch distance of approximately $83.5 \mu \mathrm{m}$ with depth length of $426.1 \mathrm{~nm}$. It was then followed by delamination, Lc2 at the scratch distance of approximately $395.7 \mu \mathrm{m}$ with depth length of $1731.2 \mathrm{~nm}$. The delamination became more severe until the coating was completely scratched off from the substrate as the load depth increases [47]. At the total exposure of the substrate, Lc3 occurred at a scratch distance of $637.5 \mu \mathrm{m}$ with depth length of $2780.8 \mathrm{~nm}$. Microhardness test was quantified at load of $1.916 \mathrm{~N}(0.2 \mathrm{~kg})$ where the pyramidal indenter was pressed on the coating's surfaces for $5 \mathrm{~s}$ until the coating was delaminated. The details about the hardness of coating were recorded as presented in Figure 8. In this test, the hardness of coating was $734 \mathrm{HV}$ with the average length of scratch was $22.48 \mu \mathrm{m}$.

3.5. Antifog Analysis. Fog testing is commonly conducted above the hot boiling bath $[42,43]$ or inside the freezer or refrigerator [44]. Figure 9 displays the formation of fog above the bare glass and coated glass surfaces. The obtained result from Figure 9(a) showed that the large droplets appear on the bare glass substrate whereas in Figure 9(b), the droplets are disappeared on the modified $\mathrm{PDMS} / \mathrm{TiO}_{2}$ coating after the condensation process. In general, the droplets scatter the incident light and degrade the transparency of glass substrate $[10,45,46]$. The superhydrophilic surface is strongly attracted to the adhered fog and spread the fog droplets like thin membrane due to its high surface energy. The modified $\mathrm{PDMS} / \mathrm{TiO}_{2}$ coating is completely dry after $1 \mathrm{~min}$ for the first test and about $3 \mathrm{~min}$ for the second test under room temperature. Under the same conditions, the droplets absolutely disappeared on the bare glass after 20 min for the first test and about $25 \mathrm{~min}$ for the second test. It is worth mentioning that further protection against fog can be achieved by increasing the hydrophilicity of the glass substrate.

3.6. Self-Cleaning Analysis. Self-cleaning test have been carried out by a simple approach and cost-efficient where the diluent-ketchup solution are designed as dirt and was demonstrated on the bare glass and modified $\mathrm{PDMS} / \mathrm{TiO}_{2}$ coated glass. Figure 10 revealed the self-cleaning property of the bare glass and modified $\mathrm{PDMS} / \mathrm{TiO}_{2}$-coated glass. The bare glass failed to resist the strong adhesion of dirt and dirt streaks on its clear surface as depicted in Figure 10(a). 


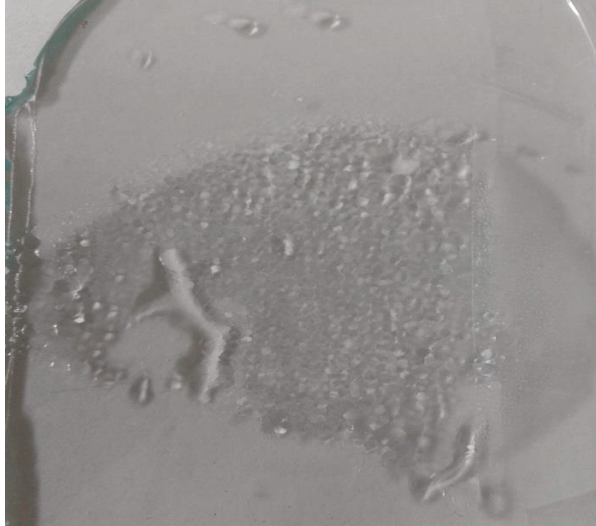

(a)

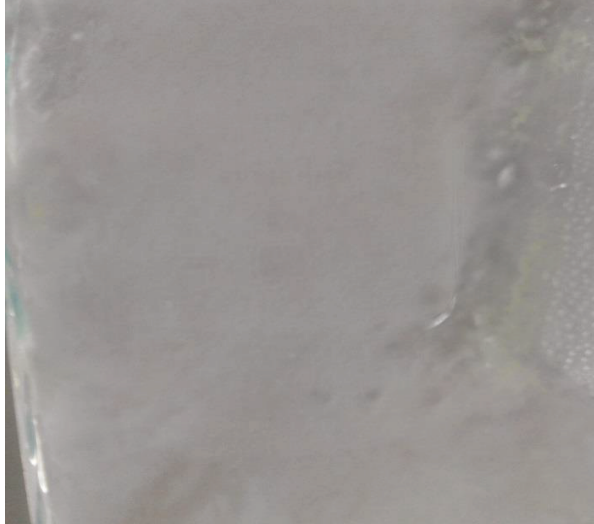

(b)

Figure 9: The formation of fog on the (a) bare glass and (b) coated glass.

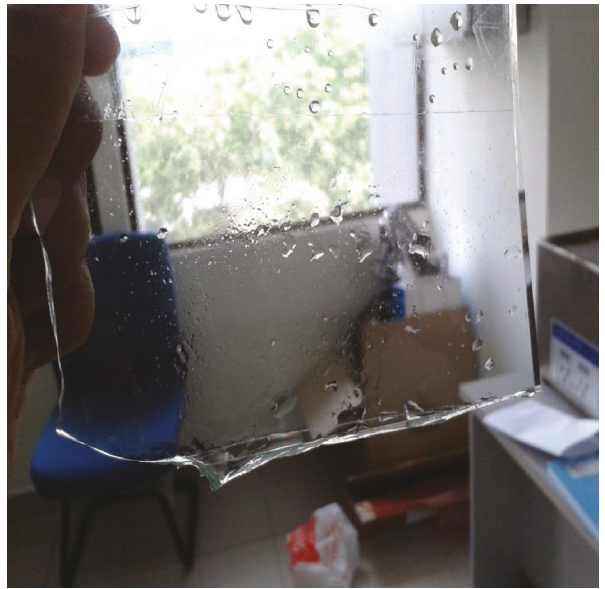

(a)

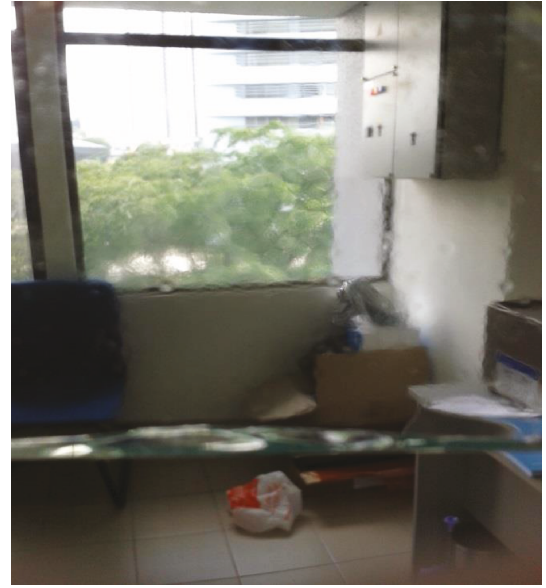

(b)

Figure 10: The formation of the dirt layer on (a) bare glass and (b) coated glass.

It can be understood that the bare glass possesses a poor self-cleaning property. The absence of the dirt layer on the modified PDMS/TiO 2 -coated glass in Figure 10(b) has represented that the superhydrophilic surface expelled the dirt by a spreading mechanism. The spreading of dirt across the superhydrophilic surface forms a thin layer of dirt. In this case, the dirt layer flowed through the micro- and nanoparticles of the modified $\mathrm{PDMS} / \mathrm{TiO}_{2}$-coated glass. With the assistance of water, the coating system can achieve an optimum self-cleaning efficiency against dirt. Nonphotocatalyst hydrophilic coating can sweep the dust downward by the influence of gravity and rain water stream [48]. The efficient water harvesting from air moisture has addressed a great solution for water shortage issues. Seo et al. [49] have reported that their superhydrophilic silicone oil coating can harvest more dew compared to superhydrophobic coating. In dew harvesting, the water is totally captured via condensation only because no vapor stream is supplied to the surface. Similar observation was observed by Choo et al. [50] where their superhydrophilic $\mathrm{TiO}_{2}$ coating was completely wetted and spread the air moisture into water film after placing the coating inside sufficient vapor pressure at $25^{\circ} \mathrm{C}$ and humidity is maintained at 92-95\%, respectively. Small water droplets are gathered together to form the thin film of the water layer during condensation and might be sufficient to expel the dirt away from the superhydrophilic surface.

3.7. Rainfall Spraying Test. Rainfall causes the adhesion of dry dust on the glass surfaces which would degrade the transparency of the glass panel. The water vapor from the rainfalls scatters the transmission of light through the glass panel. In this study, water spraying is modeled as the rainfall on the bare glass plate and modified $\mathrm{PDMS} / \mathrm{TiO}_{2}$ glass substrate. The obtained result from Figure 11(a) showed that the large droplets and water streaks appear on the bare glass substrate. The bare glass substrate recorded the blurry view due to the presence of water droplets and water streaks. In contrast, the transparency of the modified $\mathrm{PDMS} / \mathrm{TiO}_{2}$ coating shows insignificant change as shown in Figure 11(b) that could be inferred to the tendency of water droplets to spread over the surface like a thin film. Thin film layer of water possesses a large surface area on the coated glass substrate which is contributed to a higher evaporation rate than the bare glass. 


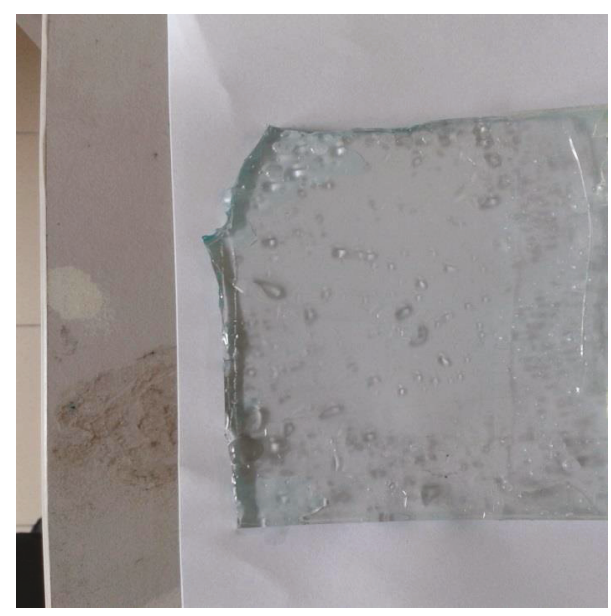

(a)

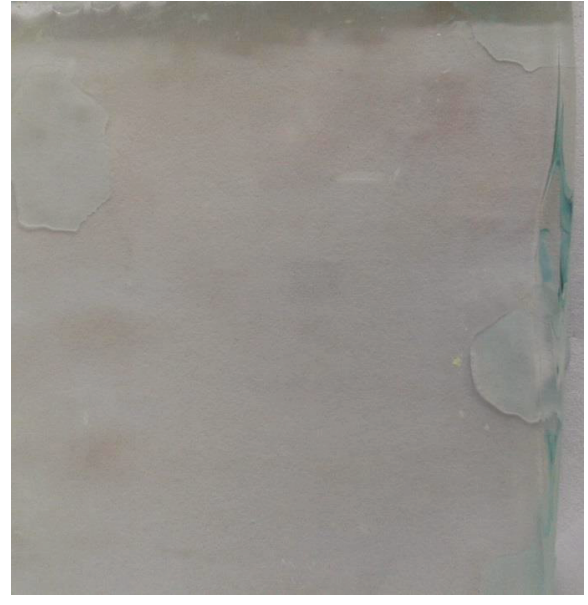

(b)

FIgURE 11: (a) Water droplets and water streaks appear on the bare glass surfaces. (b) The thin film layer of water is formed above the coated glass surface.

\section{Conclusion}

Transparent superhydrophilic coating of modified PDMS/ $\mathrm{TiO}_{2}$ has been successfully developed on the glass substrate by using simple technique, low-cost fabrication procedure, and flexible preparation. This work research is objected to evaluate the functionality and the endurance level of superhydrophilic coating against variables such as fog, dirt, and rainfall spraying. The addition of $\mathrm{TiO}_{2}$ micro- and nanoparticles within the polymer matrix demonstrated an excellent hydrophilicity as low as $4.2^{\circ}$ even without thermal treatment. That high hydrophilicity is attributed to the increase in surface roughness as shown by FESEM micrograph and nanograph. The WCA of coated glass is maintained as low as $10.4^{\circ}$ after exposing to the dark environment for 6 days which indicates that the coating experiences good durability in the dark environment. Apart from that, the coating also demonstrated excellent durability under prolonged UV light exposure where the WCA of coating showed no significant change after illuminated with UV light for 6 days. Based on the microhardness test and microscratch test, the mechanical properties such as adhesion of the superhydrophilic coating to the substrate are very strong and also have a high hardness value that is $734 \mathrm{HV}$. The clear distinction between the modified $\mathrm{PDMS} / \mathrm{TiO}_{2}$-coated glass and the bare glass substrate has been established from antifog testing and self-cleaning performance, where the modified $\mathrm{PDMS} / \mathrm{TiO}_{2}$-coated glass substrate completely expels the diluent-ketchup solution compared to the bare glass substrate. The antifog analysis reveals that the modified $\mathrm{PDMS} / \mathrm{TiO}_{2}$ coating has great antifog properties as no water droplets appeared on its superhydrophilic surface. The thin film of water disappeared completely from the modified $\mathrm{PDMS} / \mathrm{TiO}_{2}$ coating after 1 min only under room temperature. In contrast, the bare glass substrate was covered by the large droplets and completely dry after $20 \mathrm{~min}$. The modified $\mathrm{PDMS} / \mathrm{TiO}_{2}$ coating also exhibit antiwater streak behavior as the coating showed no signature of adhered droplets and streaks after undergoing water spraying for $5 \mathrm{~min}$.

\section{Data Availability}

The authors give permission for publisher and readers to access all data related to the findings in this article by providing the data file in PDF format. Any accessibility to all data is open for readers, and these included the following: (1) All the data (Figure 1: the experiment setup for rainfall spraying; Figure 2: (a) the water CA of bare glass, (b) water CA of superhydrophilic coating, and (c) the water droplet spreading as thin film layer; Figure 3: the water CA on superhydrophilic surface after (a) 2 days, (b) 4 days, and (c) 6 days and (d) the relationship between water CA and time of exposure is plotted in the graph; Figure 4: (a) the surface morphology of bare glass surface and (b) the surface morphology of $\mathrm{TiO}_{2} / \mathrm{PDMS}$ coating under magnification of $5 \mu \mathrm{m}$ and $500 \mathrm{~nm}$; Figure 5: the formation of fog on the (a) bare glass and (b) coated glass; Figure 6: the formation of the dirt layer on (a) bare glass and (b) coated glass; and Figure 7: (a) water droplets and water streaks appear on the bare glass surfaces and (b) the thin film layer of water is formed above the coated glass surface) which were presented in the finding of this study are raw data, and it was not published elsewhere and may be released upon application to the UM Power Energy Dedicated Advanced Centre (UMPEDAC), University of Malaya, Level 4, Jalan Pantai Baharu, 59990 Kuala Lumpur, Malaysia, where they can contact Dr. B. Vengadaesvaran (venga@um.edu.my). (2) All the data used to support the findings of this study are available and have been included within the article.

\section{Conflicts of Interest}

The authors declare that they have no conflicts of interest.

\section{Acknowledgments}

The authors thank the technical and financial assistance of UM Power Energy Dedicated Advanced Centre (UMPEDAC) and the Higher Institution Centre of Excellence 
(HICoE) Program Research Grant, UMPEDAC-2016 (MOHE HICOE-UMPEDAC).

\section{References}

[1] W. Sangchay, "The self-cleaning and photocatalytic properties of $\mathrm{TiO}_{2}$ doped with $\mathrm{SnO}_{2}$ thin films preparation by sol-gel method," Energy Procedia, vol. 89, pp. 170-176, 2016.

[2] L. B. Brown, A. M. Anderson, and M. K. Carroll, "Fabrication of titania and titania-silica aerogels using rapid supercritical extraction," Journal of Sol-Gel Science and Technology, vol. 62, no. 3, pp. 404-413, 2012.

[3] C. H. Kwon, J. H. Kim, I. S. Jung, H. Shin, and K. H. Yoon, "Preparation and characterization of $\mathrm{TiO}_{2}-\mathrm{SiO}_{2}$ nanocomposite thin films," Ceramics International, vol. 29, no. 8, pp. 851-856, 2003.

[4] L. Ye, Y. Zhang, C. Song, Y. Li, and B. Jiang, "A simple sol-gel method to prepare superhydrophilic silica coatings," Materials Letters, vol. 188, pp. 316-318, 2017.

[5] Y. Jia, G. Liu, X. Wu, H. Liu, R. Yue, and Y. Chen, “Anti-fogging and anti-reflective silica nanofibrous film fabricated by seedless flame method," Materials Letters, vol. 108, pp. 200203, 2013.

[6] Y. Chen, C. Zhang, W. Huang et al., "Synthesis of porous $\mathrm{ZnO} / \mathrm{TiO}_{2}$ thin films with superhydrophilicity and photocatalytic activity via a template-free sol-gel method," Surface and Coatings Technology, vol. 258, pp. 531-538, 2014.

[7] E. J. Park, A. Dollinger, I. H. Kim, H. O. Seo, G. Gantefoer, and Y. D. Kim, "Fabrication of a transparent and superhydrophilic window by depositing $\mathrm{WO}_{\mathrm{X}}$ nanoparticles via magnetron sputtering onto a glass," Surfaces and Interfaces, vol. 8, pp. 8-14, 2017.

[8] A. Syafiqa, A. K. Pandeya, N. N. Adzmana, and Nasrudin Abd Rahim, "Advances in approaches and methods for selfcleaning of solar photovoltaic panels," Solar Energy, vol. 162, pp. 597-619, 2014.

[9] T. Adachi, S. S. Latthe, S. W. Gosavi et al., "Photocatalytic, superhydrophilic, self-cleaning $\mathrm{TiO}_{2}$ coating on cheap, light-weight, flexible polycarbonate substrates," Applied Surface Science, vol. 458, pp. 917-923, 2018.

[10] F. Ç. Cebeci, Z. Wu, L. Zhai, R. E. Cohen, and M. F. Rubner, "Nanoporosity-driven superhydrophilicity: a means to create multifunctional antifogging coatings," Langmuir, vol. 22, no. 6, pp. 2856-2862, 2006.

[11] X. Du, Y. Xing, M. Zhou et al., "Broadband antireflective superhydrophilic antifogging nano-coatings based on threelayer system," Microporous and Mesoporous Materials, vol. 255, pp. 84-93, 2018.

[12] L. Zhang, R. Dillert, D. Bahnemann, and M. Vormoor, "Photoinduced hydrophilicity and self-cleaning: models and reality," Energy \& Environmental Science, vol. 5, no. 6, pp. 74917507, 2012.

[13] X. Z. Li, F. B. Li, C. L. Yang, and W. K. Ge, "Photocatalytic activity of $\mathrm{WO}_{\mathrm{x}}-\mathrm{TiO}_{2}$ under visible light irradiation," Journal of Photochemistry and Photobiology A: Chemistry, vol. 141, no. 2-3, pp. 209-217, 2001.

[14] N. C. Khang, N. van Khanh, N. H. Anh, D. T. Nga, and N. van Minh, "The origin of visible light photocatalytic activity of $\mathrm{N}$ doped and weak ferromagnetism of Fe-doped $\mathrm{TiO}_{2}$ anatase," Advances in Natural Sciences: Nanoscience and Nanotechnology, vol. 2, no. 1, article 015008, 2011.
[15] W. Zhao, W. Ma, C. Chen, J. Zhao, and Z. Shuai, "Efficient degradation of toxic organic pollutants with $\mathrm{Ni}_{2} \mathrm{O}_{3} / \mathrm{TiO}_{2}{ }_{x} \mathrm{~B}_{x}$ under visible irradiation," Journal of the American Chemical Society, vol. 126, no. 15, pp. 4782-4783, 2004.

[16] S. Sakthivel and H. Kisch, "Daylight photocatalysis by carbonmodified titanium dioxide," Angewandte Chemie International Edition, vol. 42, no. 40, pp. 4908-4911, 2003.

[17] R. Asahi, T. Morikawa, T. Ohwaki, K. Aoki, and Y. Taga, "Visible-light photocatalysis in nitrogen-doped titanium oxides," Science, vol. 293, no. 5528, pp. 269-271, 2001.

[18] S. Sato, R. Nakamura, and S. Abe, "Visible-light sensitization of $\mathrm{TiO}_{2}$ photocatalysts by wet-method N doping," Applied Catalysis A: General, vol. 284, no. 1-2, pp. 131-137, 2005.

[19] J. C. Yu, W. Ho, J. Yu, H. Yip, P. K. Wong, and J. Zhao, "Efficient visible-light-induced photocatalytic disinfection on sulfur-doped nanocrystalline titania," Environmental Science \& Technology, vol. 39, no. 4, pp. 1175-1179, 2005.

[20] J. C. Yu, Yu, Ho, Jiang, and Zhang, "Effects of F-doping on the photocatalytic activity and microstructures of nanocrystalline $\mathrm{TiO}_{2}$ powders," Chemistry of Materials, vol. 14, no. 9, pp. 3808-3816, 2002.

[21] W. B. Carlson, A. Sjong, F. Wan, and T. Londergan, "Inorganic hydrophilic self-cleaning coatings," 2012, Google Patents US20140045677A1.

[22] F. P. Torgal, J. A. Labrincha, M. V. Diamanti, C.-P. Yu, and H.-K. Lee, Biotechnologies and Biomimetics for Civil Engineering, Springer, 2015.

[23] T. Ogawa, N. Murata, and S. Yamazaki, "Sol-gel products news," Journal of Sol-Gel Science and Technology, vol. 27, no. 2, pp. 237-238, 2003.

[24] J. Zhang, X. Lu, W. Huang, and Y. Han, "Reversible superhydrophobicity to superhydrophilicity transition by extending and unloading an elastic polyamide film," Macromolecular Rapid Communications, vol. 26, no. 6, pp. 477-480, 2005.

[25] Y. Jiang, Z. Wang, X. Yu et al., "Self-assembled monolayers of dendron thiols for electrodeposition of gold nanostructures: toward fabrication of superhydrophobic/superhydrophilic surfaces and pH-responsive surfaces," Langmuir, vol. 21, no. 5, pp. 1986-1990, 2005.

[26] J. Chen, L. Zhang, Z. Zeng et al., "Facile fabrication of antifogging, antireflective, and self-cleaning transparent silica thin coatings," Colloids and Surfaces A: Physicochemical and Engineering Aspects, vol. 509, pp. 149-157, 2016.

[27] W. Zhang, M. Kalulu, X. H. Wang, X. K. Xia, X. L. Han, and Y. Jiang, "Reverse hydrophobic PDMS surface to hydrophilic by 1-step hydrolysis reaction," Polymers for Advanced Technologies, vol. 29, no. 7, pp. 2103-2109, 2018.

[28] R. Rahimi, M. Ochoa, A. Donaldson et al., “A Janus-paper PDMS platform for air-liquid interface cell culture applications," Journal of Micromechanics and Microengineering, vol. 25, no. 5, article 055015, 2015.

[29] D. Wu, B. Zhao, Z. Dai, J. Qin, and B. Lin, "Grafting epoxymodified hydrophilic polymers onto poly (dimethylsiloxane) microfluidic chip to resist nonspecific protein adsorption," Lab on a Chip, vol. 6, no. 7, pp. 942-947, 2006.

[30] S. Hemmilä, J. V. Cauich-Rodríguez, J. Kreutzer, and P. Kallio, "Rapid, simple, and cost-effective treatments to achieve longterm hydrophilic PDMS surfaces," Applied Surface Science, vol. 258, no. 24, pp. 9864-9875, 2012.

[31] E. Vasilaki, M. Vamvakaki, and N. Katsarakis, "Complex $\mathrm{ZnO}-\mathrm{TiO}_{2}$ core-shell flower-like architectures with enhanced 
photocatalytic performance and superhydrophilicity without UV irradiation," Langmuir, vol. 34, no. 31, pp. 9122-9132, 2018.

[32] Z. Duan, Y. Zhu, P. Ren et al., "Non-UV activated superhydrophilicity of patterned Fe-doped $\mathrm{TiO}_{2}$ film for anti-fogging and photocatalysis," Applied Surface Science, vol. 452, pp. 165-173, 2018.

[33] Y. Li, B. Xia, and B. Jiang, "Thermal-induced durable superhydrophilicity of $\mathrm{TiO}_{2}$ films with ultra-smooth surfaces," Journal of Sol-Gel Science and Technology, vol. 87, no. 1, pp. 50-58, 2018.

[34] X. Cui, G. Zhu, Y. Pan et al., "Polydimethylsiloxane-titania nanocomposite coating: fabrication and corrosion resistance," Polymer, vol. 138, pp. 203-210, 2018.

[35] H. P. Long, C. C. Lai, and C. K. Chung, "Polyethylene glycol coating for hydrophilicity enhancement of polydimethylsiloxane self-driven microfluidic chip," Surface and Coatings Technology, vol. 320, pp. 315-319, 2017.

[36] M. A. M. L. de Jesus, J. T. da Silva Neto, G. Timò, P. R. P. Paiva, M. S. S. Dantas, and A. de Mello Ferreira, "Superhydrophilic self-cleaning surfaces based on $\mathrm{TiO}_{2}$ and $\mathrm{TiO}_{2} / \mathrm{SiO}_{2}$ composite films for photovoltaic module cover glass," Applied Adhesion Science, vol. 3, no. 1, p. 5, 2015.

[37] A. Tricoli, M. Righettoni, and S. E. Pratsinis, "Anti-fogging nanofibrous $\mathrm{SiO}_{2}$ and nanostructured $\mathrm{SiO}_{2}-\mathrm{TiO}_{2}$ films made by rapid flame deposition and in situ annealing," Langmuir, vol. 25, no. 21, pp. 12578-12584, 2009.

[38] X. Liu, X. Du, and J. He, "Hierarchically structured porous films of silica hollow spheres via layer-by-layer assembly and their Superhydrophilic and antifogging properties," Chemphyschem, vol. 9, no. 2, pp. 305-309, 2008.

[39] Z. Yi, L. Zhu, Y. Xu, J. Jiang, and B. Zhu, "Polypropylene glycol: the hydrophilic phenomena in the modification of polyethersulfone membranes," Industrial \& Engineering Chemistry Research, vol. 50, no. 19, pp. 11297-11305, 2011.

[40] M. F. Refojo and H. Yasuda, "Hydrogels from 2-hydroxyethyl methacrylate and propylene glycol monoacrylate," Journal of Applied Polymer Science, vol. 9, no. 7, pp. 2425-2435, 1965.

[41] C. Y. Jimmy, J. Yu, H. Y. Tang, and L. Zhang, "Effect of surface microstructure on the photoinduced hydrophilicity of porous $\mathrm{TiO}_{2}$ thin films," Journal of Materials Chemistry, vol. 12, no. 1, pp. 81-85, 2002.

[42] Y. Chen, Y. Zhang, L. Shi et al., "Transparent superhydrophobic/superhydrophilic coatings for self-cleaning and anti-fogging," Applied Physics Letters, vol. 101, no. 3, article 033701, 2012.

[43] Q. Shang and Y. Zhou, "Fabrication of transparent superhydrophobic porous silica coating for self-cleaning and anti-fogging," Ceramics International, vol. 42, no. 7, pp. 8706-8712, 2016.

[44] M. H. M. A. Shibraen, H. Yagoub, X. Zhang, J. Xu, and S. Yang, "Anti-fogging and anti-frosting behaviors of layer-by-layer assembled cellulose derivative thin film," Applied Surface Science, vol. 370, pp. 1-5, 2016.

[45] H. Zhao and D. Beysens, "From droplet growth to film growth on a heterogeneous surface: condensation associated with a wettability gradient," Langmuir, vol. 11, no. 2, pp. 627-634, 1995.

[46] L. Wu and J. Baghdachi, Functional Polymer Coatings: Principles, Methods, and Applications, John Wiley \& Sons, 2015.
[47] A. R. Rafieerad, A. R. Bushroa, B. Nasiri-Tabrizi et al., "Mechanical properties, corrosion behavior and in-vitro bioactivity of nanostructured $\mathrm{Pd} / \mathrm{PdO}$ coating on $\mathrm{Ti}-6 \mathrm{Al}-7 \mathrm{Nb}$ implant," Materials \& Design, vol. 103, pp. 10-24, 2016.

[48] A. Syafiq, A. K. Pandey, N. N. Adzman, and N. A. Rahim, "Advances in approaches and methods for self-cleaning of solar photovoltaic panels," Solar Energy, vol. 162, pp. 597619, 2018.

[49] D. Seo, J. Lee, C. Lee, and Y. Nam, "The effects of surface wettability on the fog and dew moisture harvesting performance on tubular surfaces," Scientific Reports, vol. 6, no. 1, p. 24276, 2016.

[50] S. Choo, H.-J. Choi, and H. Lee, "Water-collecting behavior of nanostructured surfaces with special wettability," Applied Surface Science, vol. 324, pp. 563-568, 2015. 


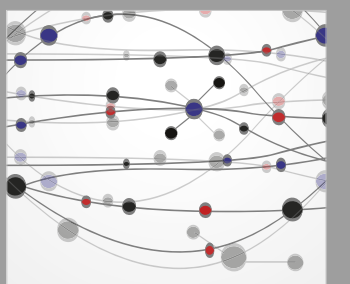

The Scientific World Journal
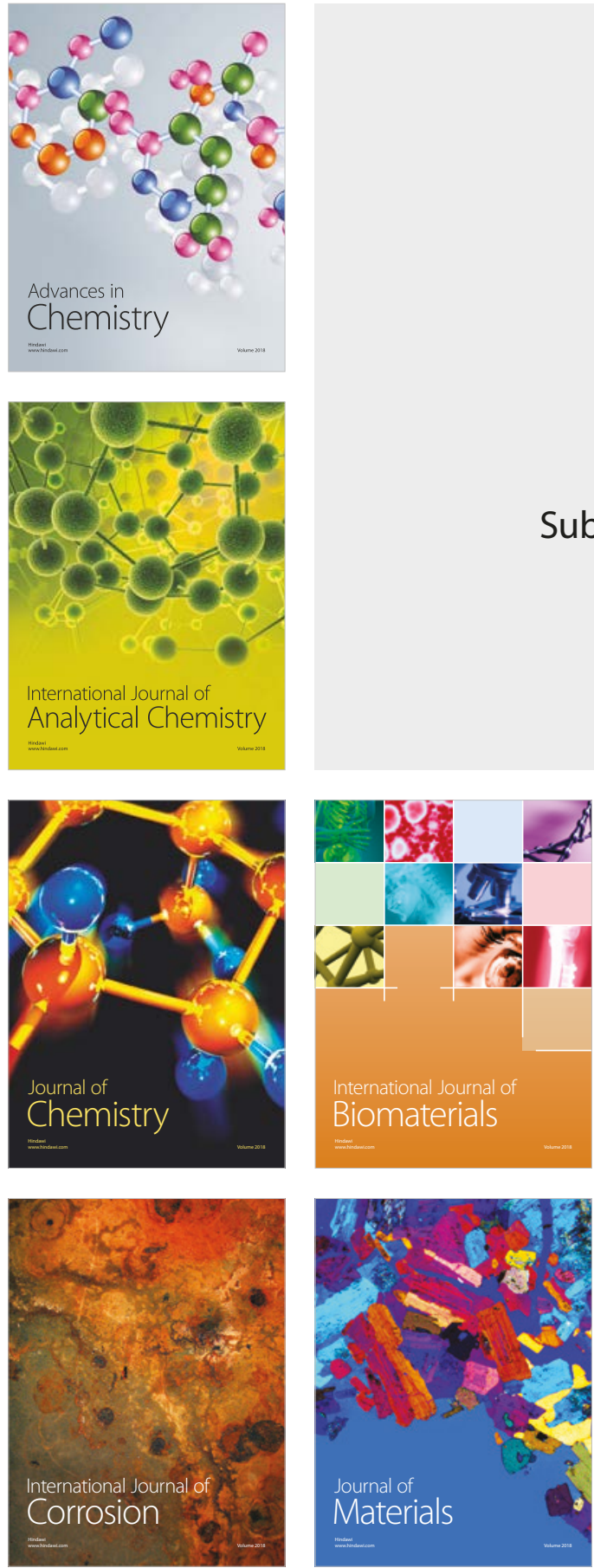

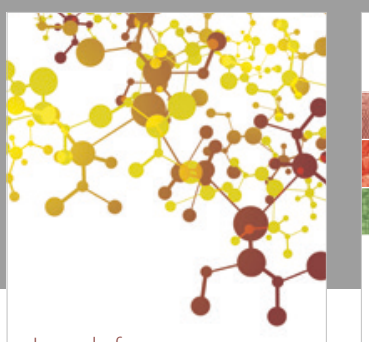

Journal of

Applied Chemistry
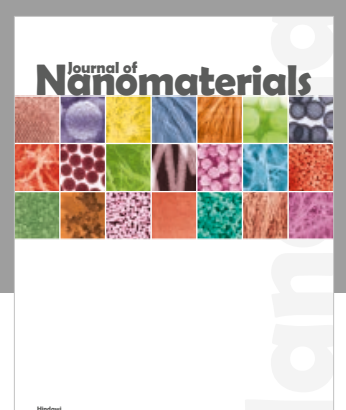

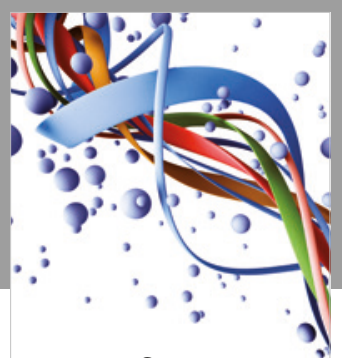

Scientifica

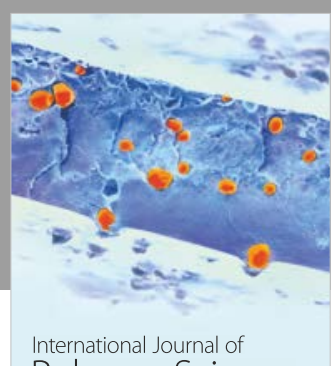

Polymer Science

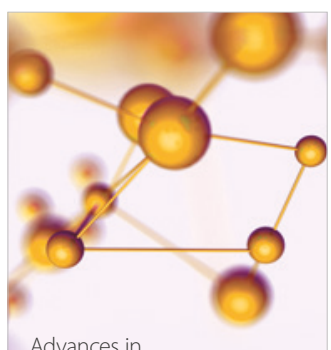

Physical Chemistry
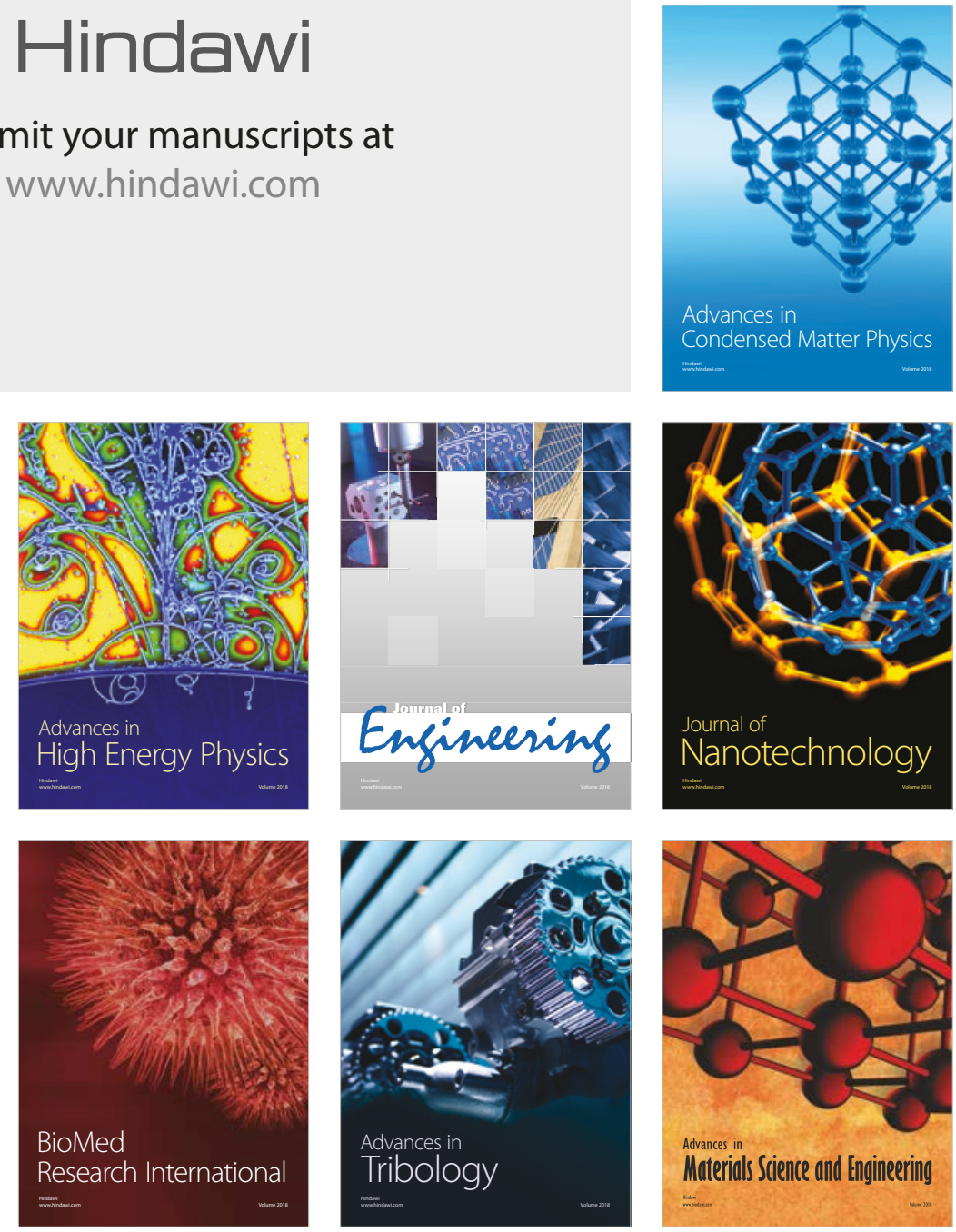